\title{
Meta-analysis of the efficacy and safety of pantoprazole in the treatment and symptom relief of patients with gastroesophageal reflux disease - PAN-STAR
}

\author{
Andrzej Dabrowski ${ }^{1}$, Borut Štabuc ${ }^{2}$, Leonid Lazebnik ${ }^{3}$ \\ ${ }^{1}$ Department of Gastroenterology and Internal Medicine, Medical University of Bialystok, Bialystok, Poland \\ 2Department of Gastroenterology, Division of Internal Medicine, University Medical Centre Ljubljana, University of Ljubljana, \\ Ljubljana, Slovenia \\ ${ }^{3}$ Department of Outpatient Therapy, Moscow State University of Medicine and Dentistry named after A. I. Evdokimov, Moscow, \\ Russia
}

Gastroenterology Rev 2018; 13 (1): 6-15

DOI: https://doi.org/10.5114/pg.2018.74556

Key words: gastroesophageal reflux disease, heartburn, pantoprazole, quality of life.

Address for correspondence: Prof. Andrzej Dabrowski MD, PhD, Department of Gastroenterology and Internal Medicine, Medical University of Bialystok, 24 A Skłodowskiej-Curie St, 15-276 Bialystok, Poland, phone: +48 85746 8234, e-mail: adabrows@umb.edu.pl

\begin{abstract}
Introduction: Proton pump inhibitors therapy success in the treatment of gastroesophageal reflux disease (GERD) is a difficult task because the extent of mucosal damage has no relation with the severity of the symptoms.

Aim: To establish the efficacy of pantoprazole treatment in patients with erosive reflux disease (ERD) and in those with non-erosive reflux disease (NERD), by assessing symptom relief and quality of life. Treatment duration and adverse events associated with pantoprazole treatment were analysed.

Material and methods: This meta-analysis was based on three multicentre, prospective, open-label, phase IV trials conducted in Slovenia, Poland, and the Russian Federation. In total, 252 patients with GERD were included and treated with pantoprazole $40 \mathrm{mg}$ once daily for 4 or 8 weeks, depending on the fulfilment of predefined healing criteria. Symptoms were assessed by patients on a scale from 0 to 3 and the quality of life on a rating scale from 1 to 10 .

Results: Forty-five percent of patients fulfilled the healing criteria after 4 weeks of treatment, and $70 \%$ of patients after 8 weeks of treatment. Patients who failed to reach the healing criteria reported significant reduction of symptoms severity. The response to 8-week treatment was significantly higher in patients with ERD (76\%) when compared to patients with NERD (64\%). Discontinuation of treatment after 4 weeks was not associated with worsening of symptoms and did not affect quality of life. Pantoprazole treatment was associated with improvement of symptoms and the quality of life of GERD patients over 8 weeks of treatment and showed that GERD patients with persisting symptoms benefit from prolonging treatment to 8 weeks. Treatment with pantoprazole $40 \mathrm{mg}$ was very well tolerated - more than $90 \%$ of patients were without adverse events throughout the whole study and only 4 patients discontinued the treatment due to adverse events related to pantoprazole treatment.

Conclusions: Pantoprazole $40 \mathrm{mg}$ was associated with complete relief of GERD-related symptoms in the majority of patients with ERD and NERD. Furthermore, the severity of symptoms was significantly reduced in patients without complete relief of symptoms. Pantoprazole also continuously improved the quality of life of GERD patients over 8 weeks of treatment and was very well tolerated throughout the whole study. Therefore, this meta-analysis suggests that pantoprazole $40 \mathrm{mg}$ once daily is an effective and well-tolerated choice for providing symptom relief of patients with GERD.
\end{abstract}

\section{Introduction}

Gastroesophageal reflux disease (GERD) is a common condition that develops when gastroesophageal reflux causes troublesome symptoms or complications. According to the Montreal definition, the diagnosis is established upon the presence of characteristic symptoms that the patient finds disturbing, regardless of their duration. Further classification of oesophageal and extra-oesophageal syndromes is based on diagnostic procedures that prove reflux of the gastric contents or the presence of characteristic and non-characteris- 
tic syndromes or complications [1]. The prevalence of GERD in industrially developed countries is about $20 \%$ with an incidence of 4.5 per 100,000 inhabitants. Both sexes are equally prone to the disease and morbidity increases with age. Twenty to forty percent of individuals experience reflux-related symptoms at least once monthly, $12 \%$ once a week, and $5 \%$ every day $[1,2]$. Gastroesophageal reflux disease symptoms affect many aspects of patients' lives including their quality of life, physical and mental well-being, and productivity [3]. Work absenteeism and increased use of health care resources result in high costs associated with GERD $[4,5]$. Furthermore, epidemiological evidence suggests oesophageal adenocarcinoma is associated with prolonged GERD symptoms [6].

About $60 \%$ of primary care patients who suffer from untoward reflux symptoms lack endoscopically visible lesions in the oesophagus lining, while $35 \%$ of patients have reflux (erosive) oesophagitis (75\% mild corresponding categories A and B according to Los Angeles classification, and 25\% severe, corresponding category $\mathrm{C}$ or D according to the same classification). From $5 \%$ to $11 \%$ of patients can develop complications such as stricture, ulcer, or Barrett's oesophagus [7].

State-of-the-art treatment involves proton pump inhibitors (PPI), which rapidly and successfully suppress the production of gastric acid, resulting in rapid symptom relief and high rates of oesophageal healing $[8,9]$. Proton pump inhibitors treatment provides fast symptom relief but does not remove the main pathogenic factors, which leads to a high rate of relapse after successful treatment. Furthermore, PPI therapy success is a difficult task because the extent of mucosal damage has no relation with the severity of the symptoms.

The present meta-analysis of three clinical studies with similar protocols (all under the same name PANSTAR), hereafter called PAN-STAR studies, aims to further assess pantoprazole (Nolpaza ${ }^{\circledR}$ ) in clinical practice.

\section{Aim}

The primary goal of the PAN-STAR studies (Efficacy and safety of PANtoprazole in the treatment and SympTom relief in patients with gAstRoesophageal reflux disease (GERD)) was to establish the efficacy of treatment with $40 \mathrm{mg}$ of pantoprazole and the effect of treatment duration on symptom control in patients with erosive reflux disease (ERD) and in those with non-erosive reflux disease (NERD). The secondary goal was to establish the effect of this treatment on the quality of life of patients with ERD and in patients with NERD. Additionally, analysis of adverse events due to pantoprazole treatment was performed.
The studies were supported by the KRKA pharmaceutical company. However, KRKA did not support this meta-analysis.

\section{Material and methods}

The three PAN-STAR clinical studies that formed the basis for this meta-analysis included 252 patients and were conducted in Slovenia, Poland, and the Russian Federation. The first patient was enrolled on $1^{\text {st }}$ November 2009 and last patient on $6^{\text {th }}$ December 2012. The trial and all of the amendments were reviewed by Independent National Ethics Committees (IECS) in all participating countries, appointed by corresponding regulatory authorities. Additionally, the study was also approved by the Local Ethics committees, where needed. EUdraCT code: 2009-017229-20.

All studies were multicentre, prospective, open-label, phase IV, conducted in 34 medical centres. Patients were treated for 4 to 8 weeks (depending on the fulfilment of healing criteria) with gastro-resistant tablets pantoprazole (Nolpaza ${ }^{\circledR}$, produced by Krka, d. d. Novo mesto, Slovenia) in the dose of $40 \mathrm{mg}$. The tablets could not to be chewed or crushed but had to be swallowed whole one hour before a meal with some water.

The study population consisted of adult (above 18 years old) patients with gastroesophageal reflux disease of both genders. Upper endoscopy was performed at the time of inclusion in all patients to establish the presence or absence of ERD. During the study, the patients were not allowed to take any medications that could affect the results of the study (sucralfate, misoprostol, $\mathrm{H}_{2}$-receptor inhibitors, other proton pump inhibitors, ketoconazole, itraconazole). They were allowed to take antacids if necessary.

Patients with oesophageal or gastric malignancies, renal impairment (serum creatinine > $300 \mu \mathrm{mol} / \mathrm{l}$ ), those positive for Helicobacter pylori infection, patients with GERD symptoms that had been unsuccessfully treated with proton pump inhibitors during a period of 6 months prior to inclusion, those with active ulcer disease (gastric, duodenal), and patients who had been treated with a proton pump inhibitor, $\mathrm{H}_{2}$-receptor inhibitor, sucralfate, or misoprostol 30 days or less prior to the first visit were not included in the study (Figure 1).

There were three visits during the study:

- Week 0 (initial visit): Upper endoscopy was performed in all included patients and the presence or absence of ERD was recorded. All patients started treatment with pantoprazole gastro-resistant tablets in a dose of $40 \mathrm{mg}$ daily for 4 weeks.

- Week 4 (second visit): Patients were assessed for healing criteria fulfilment: absence of the primary symptom, heartburn, or regurgitation during the last 


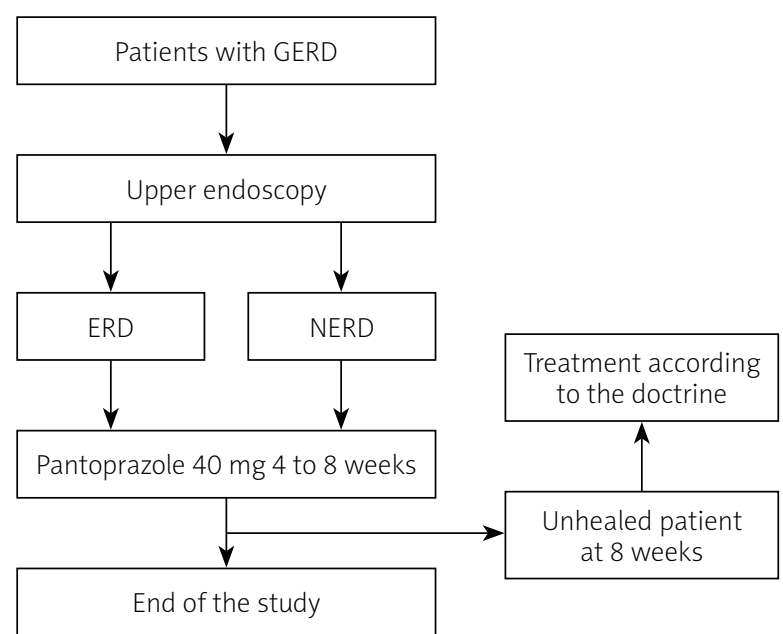

Figure 1. Scheme of the study

7 days before the control visit or its presence on not more than one day in the last week before the control visit, but in a mild form; no other symptom should be more marked than it was at the beginning of the treatment and should not be considered severe by the patient. Treatment with pantoprazole was stopped in all patients fulfilling the healing criteria. A visit for reassessment of remission was planned after 4 weeks.

Treatment with pantoprazole $40 \mathrm{mg}$ daily was continued for the next 4 weeks in all patients that failed to fulfil the healing criteria.

- Week 8 (third visit): End of the study. During this last control visit both patients in remission after 4 weeks of treatment and patients treated with pantoprazole $40 \mathrm{mg}$ for 8 weeks were examined.

All 252 patients were included in the safety analysis, and 249 patients were included in the efficacy analysis due to lack of data in 3 patients.

The severity of a symptom was assessed by patients on a scale from 0 to 3, where 0 means no symptoms; 1 - mild, occasional symptoms; 2 - moderate to severe symptoms; and 3 - severe symptoms. Patients assessed the total symptom severity score as a combined score on a scale from 0 to 3 for each symptom.

The quality of life in relation to gastroesophageal reflux disease was assessed by patients using the 1 to 10 rating scale, where 1 means worst quality of life (if the condition markedly reduces the patient's ability for daily activities) and 10 means high quality of life (if the reflux disease does not interfere with the patient's daily activities).

Because of the reasonably large sample, the asymptotic z-test was used to assess the difference between means of two variables measured in the same population. Analogously, an asymptotic 95\%-confidence inter- val $(\mathrm{Cl})$ for the difference between means was used for interval estimation.

\section{Results}

\section{Patient characteristics}

The study population consisted of 96 (38\%) males and 156 (62\%) females with an average age of 48.7 \pm 15.8 years (min. 18 years, max. 82 years). The average body mass index was $27.1 \pm 4.89 \mathrm{~kg} / \mathrm{m}^{2}(95 \% \mathrm{Cl}$ : 26.47-27.67). The average body weight did not significantly change during the study, being $77.8 \pm 16.19 \mathrm{~kg}$ (95\% Cl: $75.8-79.79)$ at the first visit and 77.03 $\pm 16.21 \mathrm{~kg}(95 \% \mathrm{Cl}: 74.91-79.16)$ at the third visit (after 8 weeks).

In total 54 (21.4\%) patients reported tobacco smoking, and 198 (78.6\%) patients were non-smokers. Two (0.8\%) included patients consumed alcohol excessively, 6 (2.4\%) patients regularly, 137 (54.4\%) patients occasionally, and 107 (42.4\%) patients did not consume alcohol.

At study entry 48 (19\%) patients had been treated with antiulcer medication during the past 30 days: 46 (18.3\%) patients had been given antacids, and 2 (0.8\%) patients had been given $\mathrm{H}_{2}$-receptor inhibitors. In the month before entering the study, 204 (81\%) patients had received no preliminary therapy with any antiulcer medication.

At the beginning of the studies 203 (80.6\%) patients were without any concomitant therapy. Forty-nine (19.4\%) patients were treated with concomitant therapy, among them 19 (7.5\%) patients with acetylsalicylic acid (ASA) and 9 (3.6\%) patients with non-steroidal anti-inflammatory drugs (NSAID). After 4 weeks of treatment 219 (86.9\%) patients were without any concomitant therapy. From the 33 (13.1\%) patients who were still receiving concomitant therapy, 11 (4.4\%) patients were treated with ASA and $7(2.8 \%)$ patients with NSAID. After 8 weeks of treatment, there were $27(10.7 \%)$ patients with concomitant therapy, among them 8 (3.2\%) patients treated with ASA and 4 (1.6\%) patients with NSAID. Two hundred and twenty-five (89.3\%) patients received no concomitant therapy.

At the time of enrolment 139 (55\%) patients had had the present symptomatic condition for more than 2 months, 43 (17\%) patients 1 to 2 months, 29 (12\%) patients 3 to 4 weeks, 28 (11\%) patients 1 to 2 weeks, and $13(5 \%)$ patients up to 1 week.

On the day of enrolment 10 (4\%) patients had had the present reflux disease more than 2 years, 139 (55\%) patients 1 to 2 years, 46 (18\%) patients 6 to 12 months, $24(10 \%)$ patients up to 6 months, and for 33 (13\%) patients it was the first occurrence. 
Score A oesophagitis according to Los Angeles classification was found in 92 (37\%) patients, score B in $41(16 \%)$ patients, and score C in $2(1 \%)$ patients. In 117 (46\%) patients no endoscopically detectable changes of the oesophageal lining were found - meaning no oesophagitis.

Hiatal hernia was found in 114 (45\%) patients, 135 (54\%) patients were without hiatal hernia, and we do not have data for $3(1 \%)$ patients.

In 13 (5\%) patients the presence of a Helicobacter pylori infection was confirmed by a positive rapid urease test. Nevertheless, these patients were included in ITT analysis. In other patients a negative urease test was found.

The study population had the following signs and symptoms: 247 (98\%) patients had heartburn, 213 (85\%) patients regurgitation, 80 (32\%) patients dysphagia, 114 (45\%) patients retrosternal pain, 152 (60\%) patients epigastric pain, 152 (60\%) patients eructation, 95 (38\%) patients nausea, 57 (23\%) patients cough, and $4(2 \%)$ patients had other signs and symptoms.

The leading symptom was the symptom that was described by the patient as the most frequent and the most disturbing, and was also the most marked; 1 patient could have one or more leading symptom/s. Heartburn was the most frequently occurring leading symptom, experienced by 233 (92\%) patients, 150 (60\%) patients experienced regurgitation, $16(6 \%)$ patients dysphagia, $33(13 \%)$ patients retrosternal pain, 65 (26\%) patients epigastric pain, 50 (20\%) patients eructation, 11 (4\%) patients nausea, 11 (4\%) patients cough, and 4 (2\%) patients experienced other signs and symptoms as leading symptoms.

At the beginning of the study, there were 50 (20\%) patients with only one leading symptom, 108 (43\%) pa-

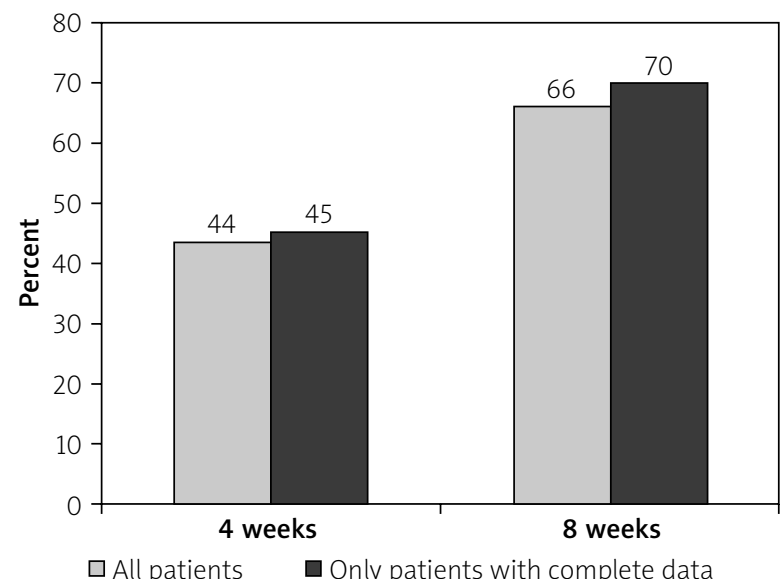

Figure 2. All patients and only patients with complete data reaching healing criteria with pantoprazole $40 \mathrm{mg}$ treatment tients with two leading symptoms, 76 (30\%) patients with three leading symptoms, 11 (4\%) patients with four leading symptoms, and 7 (3\%) patients with five leading symptoms.

\section{Treatment evaluation}

\section{Patients reaching the healing criteria}

Reaching the healing criteria was defined as the absence of the primary symptom (heartburn or regurgitation) during the last 7 days before the control visit or its presence on not more than 1 day in the last week before the control visit, but in a mild form. No other symptom should be more marked than it was at the beginning of the treatment, i.e. it must not be severe.

After 4 weeks of treatment, 110 (44\%) patients out of 249 fulfilled the healing criteria, and after 8 weeks of treatment 164 (66\%) patients out of 249 fulfilled the healing criteria. If we exclude the patients with incomplete data, then 110 (45\%) patients out of 246 fulfilled the healing criteria after 4 weeks of treatment and 164 (70\%) patients out of 234 after 8 weeks of treatment. For 15 patients, there were not enough data by which the healing criteria could be determined (Figure 2).

After 8 weeks of treatment significantly more $(p<$ 0.0001 ) erosive patients reached the healing criteria than non-erosive patients (Figure 3).

\section{Total severity score of leading symptoms}

The total severity score of leading symptoms was $4.86 \pm 2.31$ (95\% Cl: 4.57-5.15) at the first visit as assessed by 249 patients, $1.11 \pm 1.45$ ( $95 \% \mathrm{Cl}$ : 0.92-1.29) at the second visit as assessed by 245 patients, and 0.54 \pm 1.07 (95\% Cl: 0.4-0.67) at the third visit as assessed by 233 patients. The improvement in the total severity score of leading symptoms was significant $(p<0.0001)$

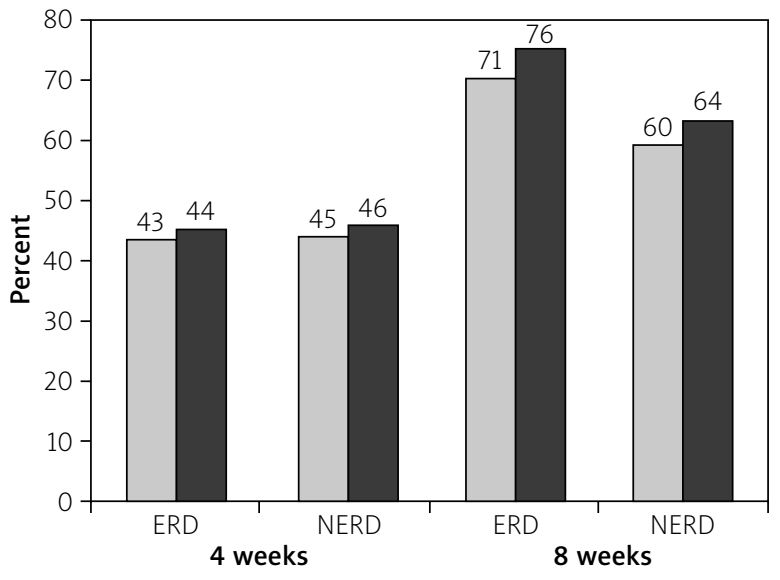

$\square$ All patients $\quad \square$ Only patients with complete data

Figure 3. Erosive and non-erosive patients reaching healing criteria 


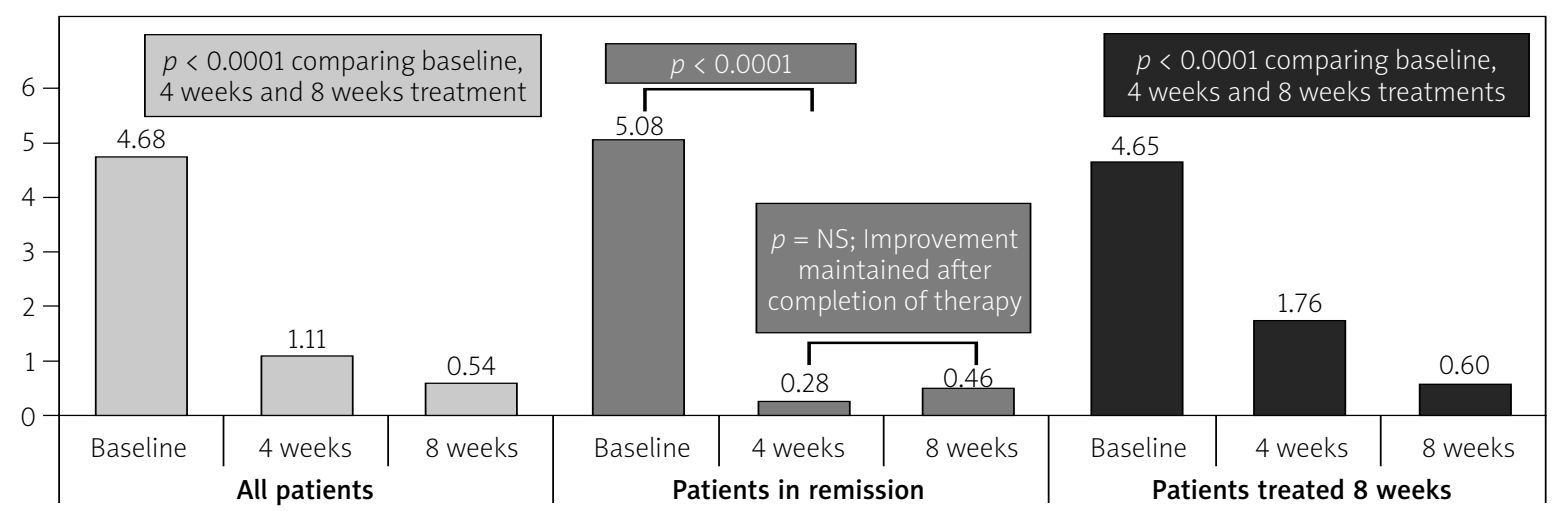

Figure 4. Total severity score of leading symptoms - comparison between groups

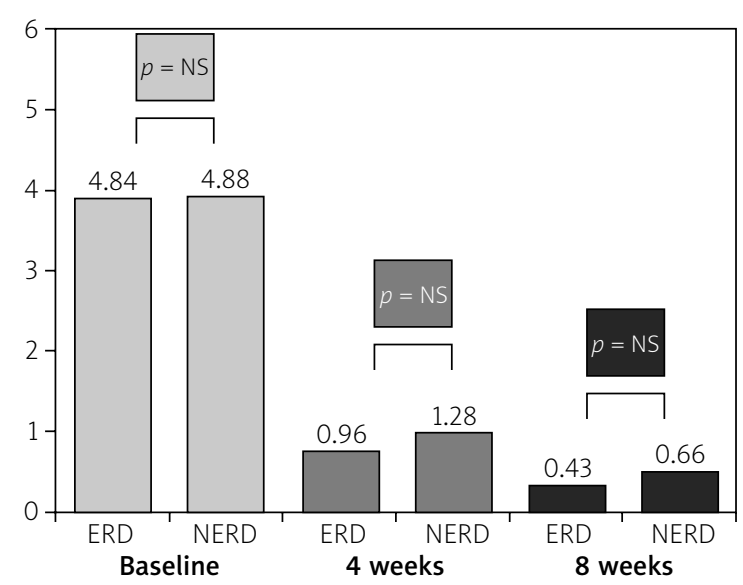

Figure 5. Total severity score of leading symptoms in erosive and non-erosive patients

throughout the study, indicating that pantoprazole had a continuous positive effect on the severity of leading symptoms during 8 weeks of treatment (Figure 4).

In the group of patients in remission after 4 weeks of treatment (and stopping treatment after 4 weeks), a sustained improvement in the total severity score of leading symptoms was demonstrated at the control visit after 8 weeks. The GERD patients treated for 8 weeks clearly reached a further improvement in the total severity score of leading symptoms after 8 weeks of treatment compared to 4 weeks of treatment (Figure 4).

The total severity score of leading symptoms was decreased to the same extent in both erosive and non-erosive patients (Figure 5).

\section{Individual symptoms}

The average score for the heartburn symptom was $2.17 \pm 0.82(95 \% \mathrm{Cl}: 2.07-2.27)$ at the first visit as assessed by 249 patients, $0.55 \pm 0.71$ (95\% Cl: 0.46-0.64) at the second visit as assessed by 245 patients, and $0.26 \pm 0.54$ (95\% Cl: $0.19-0.33)$ at the third visit as assessed by 233 patients.
The average score for the regurgitation symptom was $1.6 \pm 0.99$ (95\% Cl: $1.48-1.73$ ) at the first visit assessed by 249 patients, $0.44 \pm 0.66$ ( $95 \% \mathrm{Cl}$ : 0.36-0.52) at the second visit assessed by 245 patients, and 0.26 $\pm 0.57(95 \% \mathrm{Cl}: 0.18-0.33)$ at the third visit assessed by 233 patients.

The improvement in heartburn and regurgitation symptoms was significant $(p<0.0001)$ throughout the study, indicating that pantoprazole also had a continuous positive effect on heartburn during 8 weeks of treatment.

Next to symptoms such as heartburn and regurgitation, dysphagia, retrosternal pain, epigastric pain, eructation, nausea, and cough were also significantly reduced during the PAN-STAR studies.

\section{Total symptoms severity score}

The total symptoms severity score was $8 \pm 4.14$ ( $95 \% \mathrm{Cl}$ : 7.49-8.52) at the first visit as assessed by 249 patients, $2.03 \pm 2.42$ (95\% Cl: $1.73-2.33)$ at the second visit as assessed by 245 patients, and $1 \pm 1.8$ ( $95 \% \mathrm{Cl}$ : 0.76-1.23) at the third visit as assessed by 233 patients.

The improvement in all symptoms severity score was significant $(p<0.0001)$ throughout the study, indicating that pantoprazole had a continuous positive effect on the severity of all symptoms together during 8 weeks of treatment (Figure 6).

In the group of patients in remission after 4 weeks of treatment (and stopping treatment after 4 weeks), a sustained improvement in the total symptoms severity score was demonstrated at the control visit after 8 weeks. The GERD patients treated for 8 weeks clearly reached a further improvement in the total symptoms severity score after 8 weeks of treatment compared to 4 weeks of treatment (Figure 6).

The total symptoms severity score was decreased to the same extent in both erosive and non-erosive patients (Figure 7). 


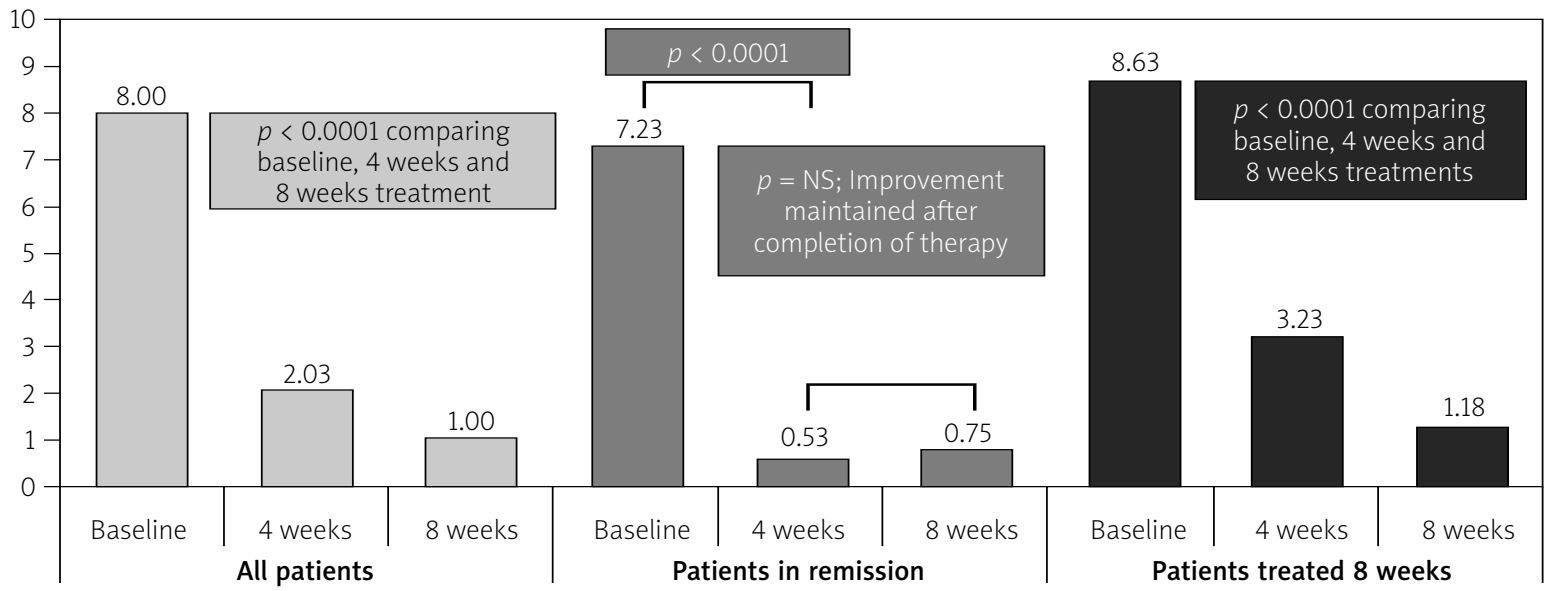

Figure 6. Total symptoms severity score - comparison between groups

The effect of treatment on the patient's quality of life

The average score for the quality of life was 4.65 \pm 2.06 (95\% Cl: 4.4-4.91) at the first visit as assessed by 249 patients, $7.61 \pm 2.01$ (95\% Cl: 7.36-7.86) at the second visit as assessed by 245 patients, and $8.41 \pm 1.83$ (ACl: $8.18,8.65)$ at the third visit as assessed by 234 patients.

The average score for the quality of life gradually increased until the end of the study. The increase was significant $(p<0.0001)$, indicating that pantoprazole has a continuous positive effect on the quality of life during 8 weeks of treatment (Figure 8).

In the group of patients in remission already after 4 weeks (and stopping treatment after 4 weeks) weeks, a sustained improvement in the quality of life was demonstrated at the control visit after 8 weeks. The GERD patients treated for 8 weeks clearly reached a further improvement in quality of life after 8 weeks of treatment compared to 4 weeks of treatment (Figure 8).
The quality of life was increased to the same extent in both erosive and non-erosive patients after 4 weeks. However, after 8 weeks of treatment a significant differ-

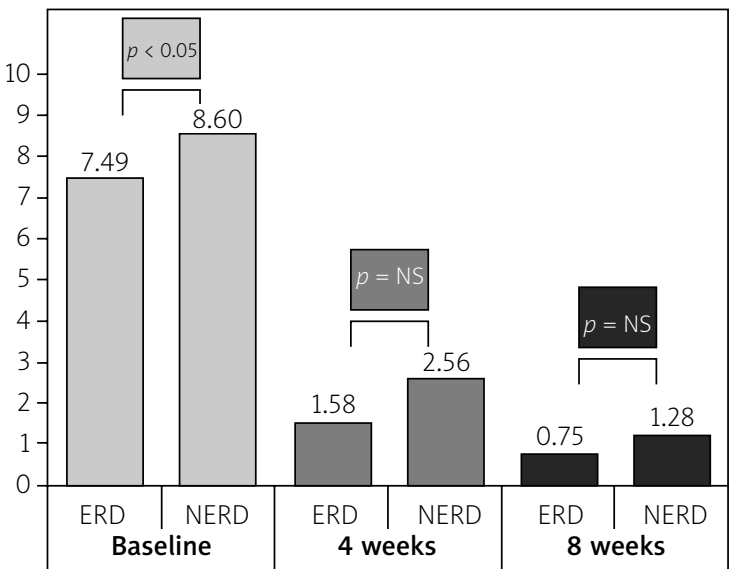

Figure 7. Total symptoms severity score in erosive and non-erosive patients

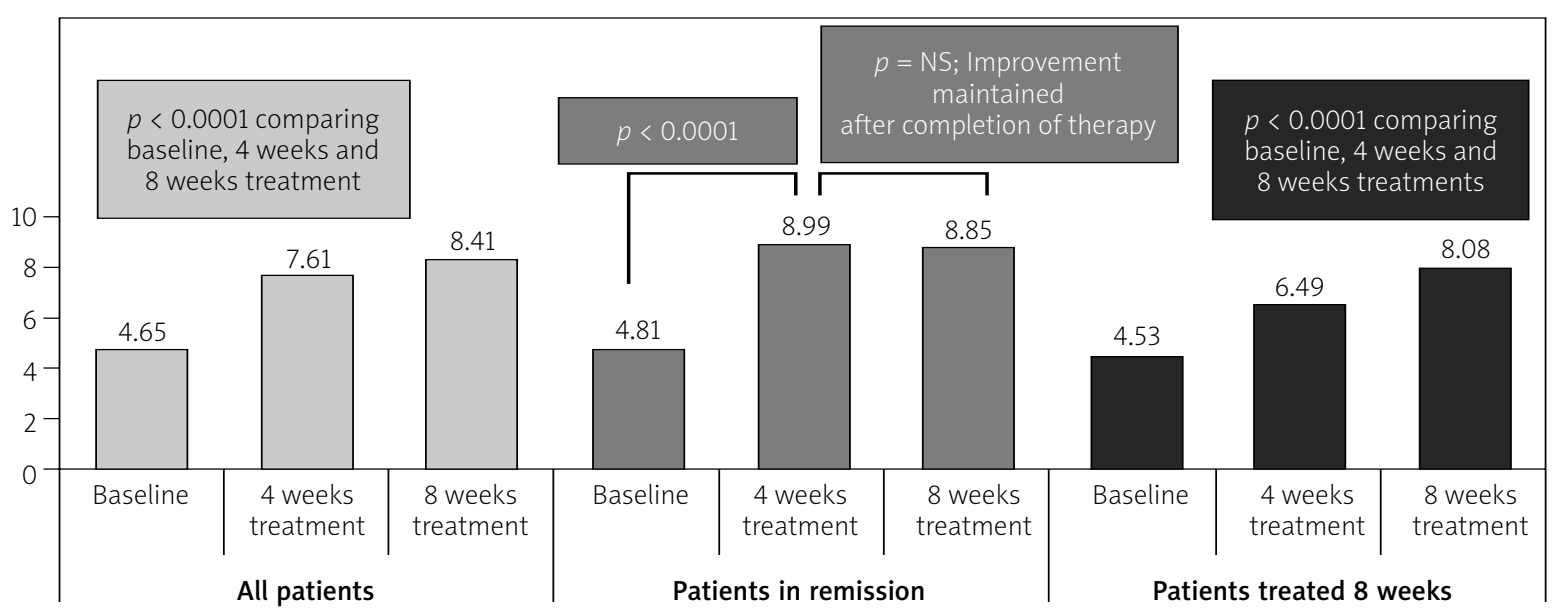

Figure 8. Quality of life, comparison between groups 


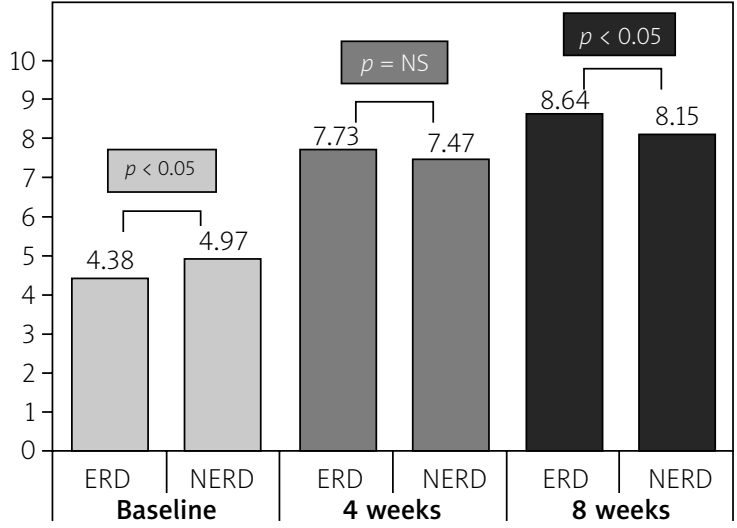

Figure 9. Quality of life in erosive and non-erosive patients

$p<0.0001$ : comparing baseline, 4 weeks and 8 weeks treatment for both groups.

ence in improvement in the quality of life $(p<0.05)$ was demonstrated in erosive patients compared to non-erosive patients (Figure 9).

\section{Safety evaluation}

The criterion for the safety evaluation was the overall incidence of drug-related adverse events (adverse reactions). All 252 patients were included in the safety analysis.

Treatment with pantoprazole $40 \mathrm{mg}$ was well tolerated. More than $90 \%$ of patients throughout the whole study period were without adverse events. Adverse reactions with causal relationship to the study medication appeared in 18 patients (7.1\% of patients) The most common adverse reactions were constipation (5 patients, $2 \%$ ), nausea (4 patients, $1.6 \%$ ), flatulence (3 patients, $1.2 \%$ ), hypersensitivity (3 patients, $1.2 \%$ ), and headache ( 3 patients, $1.2 \%$ ). Four patients discontinued the treatment due to adverse reactions after the initial visit.

\section{Discussion}

A number of multicentre, controlled, randomised studies have demonstrated that pantoprazole in daily doses of $40 \mathrm{mg}$ administered for 4-8 weeks is an optimal dosing regimen in non-erosive reflux disease and mild to moderate erosive reflux disease, compared to histamine-2-receptor antagonists $\left(\mathrm{H}_{2} \mathrm{RAs}\right)$ [10-14]. The rate of endoscopy confirmed that healing was significantly higher in patients on pantoprazole therapy compared to that observed with $\mathrm{H}_{2} \mathrm{RA}$ therapy $[10,12$, 15-19]. Pantoprazole was approved by the FDA in 2000 for the treatment of erosive esophagitis associated with GERD. It has been used in more than 100 different countries worldwide [20].
The efficacy and safety of pantoprazole for the treatment and symptom relief in patients with gastroesophageal reflux disease were studied in three multicentre, open labelled, prospective, phase IV PAN-STAR studies. The target population was selected according to typical GERD symptoms (troublesome heartburn and/or regurgitation) in all three clinical trials. Reported reflux symptoms duration was 1 to 2 years in half of the patients and $4 \%$ of included patients were symptomatic for more than 2 years. No endoscopically detectable changes of the oesophageal lining were found in $46 \%$ of patients.

Gastroesophageal reflux disease symptom profile did not differ in patients with ERD and in those with NERD. Recent studies have demonstrated that patients with NERD are more difficult to manage than those with ERD and that progression to ERD is relatively uncommon in these patients [21]. Two hundred fifty-two patients were included in this meta-analysis (efficacy analysis was performed in 249). The studied population had a mean age of $48.7 \pm 15.8$ years, and $62 \%$ of included patients were female. A relatively large proportion of included patients were non-smokers (198 patients, 78.6\%), while only 107 (42.4\%) patients denied drinking alcohol. One third of patients had accompanying diseases, of which the majority (57 patients; $22.6 \%$ ) had arterial hypertension; $19.4 \%$ of patients had concomitant therapy.

Little is known about the possible differences in the therapeutic response to the PPIs with regard to geographical and ethnic differences in patients with GERD. Small differences in the interpretation of symptoms can have a major influence on the trial results. There is frequent disagreement between everyday clinical practice and reported clinical trial results, which can be attributed to studied endpoints and selected patient population [22, 23].

A number of behavioural factors are thought to trigger GERD. Many studies identified a significant association between GERD, smoking, and alcohol consumption $[24,25]$. Furthermore, a number of significant associations were demonstrated with the use of prescription medications such as NSAIDs, anticholinergic drugs, nitrates, benzodiazepines, and calcium antagonists [2].

In general, the cure rates in GERD and the disappearance of clinical symptoms depend on baseline symptom severity and the patients' compliance with the PPI treatment [26]. The time to resolution of heartburn and other symptoms did not differ significant between different PPIs [27].

In different clinical studies using different PPIs, complete disappearance of clinical symptoms at 8 weeks of treatment was reported in $65-67 \%$ of the treated patients, and endoscopic cure was observed in 85-90\% of the patients. No significant differences between pro- 
ton pump inhibitors were observed in the rate of clinical remission of GERD and cure of ERD [28]. Seventy-thirty-two percent of GERD patients have resistant and troublesome symptoms of heartburn and regurgitation regardless of PPI therapy [29].

The results in the PAN-STAR studies show that pantoprazole in a dose of $40 \mathrm{mg}$ was found to be highly effective and safe in the treatment of GERD. In the intention-to-treat analysis, $44 \%$ of patients met the healing criteria after 4 weeks of treatment, and this number increased to $66 \%$ after a further 4 weeks of treatment. When excluding the patients with incomplete data, 110 (45\%) patients out of 246 fulfilled the healing criteria after 4 weeks of treatment and 164 (70\%) patients out of 234 after 8 weeks of treatment. The average total symptom severity score was significantly reduced after 4 weeks of treatment and decreased even further by 8 weeks (including $40 \%$ of patients in remission, who stopped treatment with pantoprazole after 4 weeks of treatment). The average symptom severity score at enrolment was 2.03 (on the scale 0-3) and 1.00 at 8 weeks. $98.4 \%$ of patients receiving pantoprazole for 4 weeks experienced significant relief of leading symptoms with the average score of $1.11 .93 .6 \%$ of patients reported average leading symptom severity score of 0.54 after 8 weeks of treatment. Both treatment durations were associated with a significant increase in the quality of life.

Pantoprazole $40 \mathrm{mg}$ demonstrated a continuous improvement of the relief of symptoms and the quality of life of GERD patients during 8 weeks of treatment, showing that GERD patients with persisting symptoms benefit from prolonging treatment to 8 weeks. At the same time, no significant increase in the severity of symptoms and no significant decrease in the quality of life were found 4 weeks after they discontinued the therapy in patients who fulfilled the healing criteria after 4 weeks of treatment. Symptom resolution rate after 4 and 8 weeks, as well as quality of life improvement, were lower in patients with NERD when compared to patients with oesophagitis. Several other recent studies report similar findings, possibly indicating that patients with NERD are a more heterogeneous population than patients with erosive disease [30, 31].

Proton pump inhibitors are generally very well tolerated, and they are rarely associated with adverse reactions. The most common adverse effects of treatment in this group of medicines are headache, nausea, diarrhoea, abdominal pain, fatigue, and dizziness [32]. Diarrhoea was observed in $4.5 \%$ of the patients during a 1-year treatment with pantoprazole, nausea in $2.7 \%$ of the patients, vomiting in $2.3 \%$ of the patients, and dizziness in $1.8 \%$ of the patients [33]. Pantoprazole was demonstrated to have a favourable tolerability profile in a British post-authorisation surveillance study in 11,541 patients, where adverse events were reported in only 107 patients. The most significant adverse reactions were diarrhoea, nausea, headache, and dizziness [34]. Recently published data have demonstrated that daily pantoprazole maintenance therapy for up to 15 years for severe acid peptic disease is effective and well tolerated with no identified safety concerns. The moderate pantoprazole-induced hypergastrinaemia was not associated with any clinically relevant transformation of gastric mucosa [35].

The results of this meta-analysis agree with these findings. More than $90 \%$ of patients were without adverse events throughout the whole study. Adverse reactions with causal relationship to the study drug appeared in $7.1 \%$ of patients. The most common adverse reactions were constipation (5 patients, $2 \%$ ), nausea (4 patients, $1.6 \%$ ), flatulence (3 patients, $1.2 \%$ ), hypersensitivity (3 patients, 1.2\%), and headache (3 patients, 1.2\%). Only 4 patients discontinued the treatment due to adverse events related to the pantoprazole treatment.

\section{Conclusions}

The results of the present meta-analysis of the PANSTAR clinical studies show that pantoprazole $40 \mathrm{mg}$ was associated with complete relief of GERD related symptoms in the majority of patients with ERD and NERD. In patients without complete relief of symptoms the severity of symptoms was significantly reduced. Furthermore, pantoprazole $40 \mathrm{mg}$ significantly improved the quality of life of treated patients and was very well tolerated throughout the whole study. Therefore, this meta-analysis suggests that pantoprazole $40 \mathrm{mg}$ once daily is an effective and well tolerated choice for providing symptom relief of patients with GERD.

\section{Acknowledgments}

Source of funding: Krka, d. d., Novo mesto.

\section{Conflict of interest}

The authors have received fees from KRKA for performing PAN-STAR studies. No payments were made to authors for performing this meta-analysis and writing of this article.

\section{List of investigators \\ Investigators from Slovenia}

1. prof. dr. Borut Štabuc, University Medical Centre Ljubljana, principal investigator

2. prim. asist. dr. Borut Kocijančič, University Medical Centre Ljubljana

3. Manfred Mervic, University Medical Centre Ljubljana 
4. Rado Janša, University Medical Centre Ljubljana

5. Andrej Gruden, University Medical Centre Ljubljana

6. Živa Mrevlje, University Medical Centre Ljubljana

7. Samo Plut, University Medical Centre Ljubljana

8. David Drobne, University Medical Centre Ljubljana

9. Katja Novak, University Medical Centre Ljubljana

10. Alojz Šmid, University Medical Centre Ljubljana

11. Aljaž Repše, University Medical Centre Ljubljana

12. Nataša Smrekar, University Medical Centre Ljubljana

13. Branko Gregorič, General Hospital Novo mesto

14. Marjan Gorenc, General Hospital Novo mesto

15. Boštjan Gorjup General Hospital Novo mesto

16. Blaž Berger, General Hospital Izola

17. Tamara Marušič, General Hospital Izola

18. Bojana Luštrek, General Hospital Izola

19. Marija Humek Petelinc, General Hospital Brežice

20. Primož Jovan, General Hospital Jesenice

21. prim. Milan Stefanovič, Diagnostic Centre Vila Bogatin Bled

22. Jasna Volfand, Diagnostic Centre Bled

23. Zdravko Tošović, Diagnostic Centre Bled

24. Ljiljana Ljepovič, Diagnostic Centre Bled

25. Miran Drenovec, Diagnostic Centre Bled

26. Dejan Urlep, Diagnostic Centre Bled

27. Jurij Bednarik, General Hospital Šempeter

28. Marko Klančič, General Hospital Šempeter

29. Bor Urbančič, General Hospital Šempeter

30. Stanislav Benedik, Private practice in Kranj

31. mag. Jože Seljak, Private practice in Nova Gorica

32. Boris Škofic, Hospital Golnik

33. Renata Šibli, General Hospital Celje

34. Boštjan Birsa, General Hospital Celje

35. Rajko Kneževič, General Hospital Celje

36. Barbara Sodin, General Hospital Celje

37. Tadeja Pačnik Vižintin, General Hospital Celje

38. Jure Zupan, General Hospital Celje

39. Marija Žnidaršič, General Hospital Celje

40. Bojan Glavnik, Private practice Endomed, Celje

41. Enriko Plevnik, General Hospital Slovenj Scorec

42. Vladimir Natek, General Hospital Slovenj Scorec

43. Zdenko Kikec, General Hospital Slovenj Scorec

44. Klemen Mojškerc, General Hospital Slovenj Scorec

45. Miroslav Vujasinović, General Hospital Slovenj Scorec

46. Sonja Puhr Moličnik, Private practice in Slovenj Scorec

47. Zdenka Čerk Speiser, General Hospital Trbovlje

48. Nataša Brglez Jurečič, General Hospital Trbovlje

49. Alenka Forte, Private practice Helix in Trbovlje

50. prof. dr. Bojan Tepeš, Private practice Abacus in Rogaška Slatina

51. mag. Zoran Stanišič, Medical Centre Rogaška Slatina

52. Anita Kek Ljubec, Medical Centre Rogaška Slatina

53. Darko Košutić, Private practice in Rogaška Slatina

54. Borut Rijavec, Hospital Topolšica

55. prof. dr. Pavel Skok, University Medical Centre Maribor

56. Maksimilijan Pocajt, University Medical Centre Maribor

57. Andreja Ocepek, University Medical Centre Maribor

58. Davorin Čeranič, University Medical Centre Maribor

59. Davorin Dajčman, University Medical Centre Maribor

60. prim. asist. Cvetka Pernat, University Medical Centre Maribor
61. mag. Žarko Pinter, Private practice Archimed, d.o.o, Maribor

62. mag. Maja Šeruga, General Hospital Murska sobota

63. Stana Šutulovič, General Hospital Murska sobota

64. Miran Gerič, General Hospital Murska sobota

65. Dejan Majc, General Hospital Murska sobota

66. Tatjana Puc Kous, Private practice in Medical Centre Radenci

67. Matjaž Brenčič, General Hospital Ptuj

68. Branko Vukasovič, General Hospital Ptuj

69. asist. Željko Perdija, General Hospital Ptuj

\section{Investigators from Poland}

1. prof. dr. hab. med. Andrzej Dąbrowski, Medical University of Bialystok, principal investigator

2. dr n. med. Grażyna Jurkowska, Medical University of Bialystok

3. Ewa Turecka-Kulesza, Medical University of Bialystok

4. prof. Jerzy Gil, Military Institute of Medicine in Warsaw

5. dr Michat Florek, Military Institute of Medicine in Warsaw

6. dr Tomasz Stelmaszuk, Military Institute of Medicine in Warsaw

7. dr Przemysław Dyrla, Military Institute of Medicine in Warsaw

\section{Investigators from the Russian Federation}

1. Leonid Lazebnik, Moscow State University of Medicine and Dentistry named after A. I. Evdokimov, principal investigator

2. Dmitriy Bordin, State Health Care Institution of Moscow city, Central Research and Development Institute of Gastroenterology, principal investigator

3. Sayar Abdulkhakov, State Educational Institution of the Higher Professional Education, Kazan State Medical University of Roszdrav

4. Elena Eremina, State Educational Institution of the Higher Professional Education, Mordovsk State University of N.P. Ogarev, Federal Agency of Education

5. Natalya Zakharova, Sankt-Petersburg State Health Care Institution, Municipal Hospital No. 26

6. Igor Ivanikov, Federal State Institution, Central Clinical Hospital with the Out-patient Clinic of Department of Presidential Affairs of the Russian Federation

7. Nonna Nikolaeva, State Educational Institution of the Higher Professional Education, Krasnoyarsk State Medical University of the prof. V.F. Voyno-Yaseneckiy, the Ministry of Health and Social Development of Russia

\section{References}

1. Vakil N, van Zanten SV, Kahrilas P, et al. The Montreal definition and classification of gastroesophageal reflux disease: a global evidence-based consensus. Am J Gastroentrol 2006; 101: 1900-20.

2. Dent J, El-Sareg HB, Wallander MA, Johansson S. Epidemiology of gastrooesophageal reflux disease: a systematic review. Gut 2005; 54: 710-7.

3. Wiklund I, Carlsson J, Vakil N. Gastroesophageal reflux symptoms and well-being in a random sample of the general population of a Swedish Community. Am J Gastroenterology 2006; 101: 18-28. 
4. Wahlqvist P, Brook RA, Campbell SM, et al. Objective measurement of work absence and on-the-job productivity: a case-control study of US employees with and without gastroesophageal reflux disease. J Occup Environ Med 2008; 50: 25-31.

5. Brook RA, Wahlqvist P, Kleinman NL, et al. Cost of gastrooesophageal reflux disease to the employer: a perspective from the United States. Aliment Pharmacol Ther 2007; 26: 889-98.

6. Lagergren J, Bergstrom R, Lindgren A, Nyren O. Symptomatic gastroesophageal reflux as a risk factor for esophageal adenocarcinoma. N Engl J Med 1999; 340: 825-31.

7. Kulig M, Nocom N, Vieth M, et al. Risk factors of gastroesophageal reflux disease: methodology and first epidemiological results of the ProGerd study. J Clin Epidem 2004; 57: 580-9.

8. Moayyedi P, Santana J, Khan M, et al. Medical treatments in the short term management of reflux oesophagitis. Cochrane Database Syst Rev 2007; 2: CD003244.

9. Wiklund I, Carlsson J, Vakil N. Gastroesofageal reflux symptoms and well-being in random sample of the general population of a Swedish community. Am J Gastroenterol 2006; 101: 18-28.

10. Cheer SM, Prakash A, Faulds D, Lamb HM. Pantoprazole: an update of its pharmacological properties and therapeutic use in the management of acid-related disorders. Drugs 2003; 63: 101-33.

11. Kahrilas PJ, Shaheen NJ, Vaezi MF, et al. American Gastroenterological Association Medical Position Statement on the management of gastroesophageal reflux disease. Gastroenterology 2008; 135: 1383-91

12. Gallo S, Dibildox M, Moguel A, et al. Clinical superiority of pantoprazole over ranitidine in the treatment of reflux esophagitis grade II and III. A prospective, double-blind, double-placebo study. Mexican clinical experience. Mexican Pantoprazole Study Group. Rev Gastroenterol Mex 998; 63: 11-6.

13. Dammann H, Von Kleist. Efficacy and tolerability of pantoprazole versus ranitidine and famotidine in patients with gastro-oesopghageal reflux disease: multicentre, open, randomised, control studies. International Clinical Practice Series 1997; 15: 23-9.

14. Richter JE, Bochenek W. Oral pantoprazole for erosive esophagitis: a placebo-controlled, randomized clinical trial. Pantoprazole US GERD Study Group. Am J Gastroenterology 2000; 95: 3071-80

15. Van Rensburg CJ, Honiball PJ, Van Zyl JH, et al. Safety and efficacy of pantoprazole $40 \mathrm{mg}$ daily as relapse prophylaxis in patients with healed reflux oesophagitis - a 2-year follow-up. Aliment Pharmacol Ther 1999; 13: 1023-8.

16. Meneghelli UG, Boaventura S, Moraes-Filho JP, et al. Efficacy and tolerability of pantoprazole versus ranitidine in the treatment of reflux esophagitis and the influence of Helicobacter pylori infection on healing rate. Dis Esophagus 2002; 15: 50-6.

17. Armstrong D, Pare P, Pericak D, Pyzyk M. Symptom relief in gastroesophageal reflux disease: a randomized, controlled comparison of pantoprazole and nizatidine in a mixed patient population with erosive esophagitis or endoscopy-negative reflux disease. Am J Gastroenterol 2001; 96: 2849-57.

18. Richter JE, Fraga P, Mack M, et al. Prevention of erosive oesophagitis relapse with pantoprazole. Aliment Pharmacol Ther 2004; 20: 567-75.
19. Metz DC, Bochenek WJ. Pantoprazole maintenance therapy prevents relapse of erosive oesophagitis. Aliment Pharmacol Ther 2003; 17: 155-64.

20. Mathews S, Reid A, Tian C, Cai Q. An update on the use of pantoprazole as a treatment for gastroesophageal reflux disease. Clin Exp Gastroenterol 2010; 3: 11-6.

21. Fass R. Erosive esophagitis and nonerosive reflux disease (NERD) - comparison of epidemiologic, physiologic, and therapeutic characteristics. J Clin Gastroenterol 2007; 41: 131-7.

22. Kang JY. Systematic review: geographical and ethnic differences in gastro-oesophageal reflux disease. Aliment Pharmacol Ther 2004; 20: 705-17.

23. El Serag H, Bechler A, Jones R. Systematic review: persistent reflux symptoms on proton pump inhibitor therapy in primary care and community studies. Aliment Pharmacol Ther 2010; 32: 720-37.

24. Locke GR III, Talley NJ, Fett SL, et al. Risk factors associated with symptoms of gastroesophageal reflux. Am J Med 1999; 106: 642-9.

25. Mohammed I, Cherkas LF, Riley SA, et al. Genetic influences in gastro-oesophageal reflux disease: a twin study. Gut 2003; 52: $1085-9$

26. Bardhan KD, Achim A, Riddermann T, et al. A clinical trial comparing pantoprazole and esomeprazole to explore the concept of achieving 'complete remission' in gastrooesophageal reflux disease. Aliment Pharmacol Ther 2007; 25: 1461-9.

27. Bardhan KD, Van Rensburg C. Comparable clinical efficacy and tolerability of $20 \mathrm{mg}$ pantoprazole and $20 \mathrm{mg}$ omeprazole in patients with grade I reflux oesophagitis. Aliment Pharmacol Ther 2001; 15: 1585-91.

28. Boparai V, Rajagopalan J, Triadafilopoulos G. Guide to the use of proton pump inhibitors in adult patients. Drugs 2008; 68: 925-47.

29. Fass R, Shapiro M, Dekel R, Sewell J. Systematic review: proton-pump inhibitor failure in gastro-oesophageal reflux disease - where next? Aliment Pharmacol Ther 2005; 22: 79-94.

30. Tepeš B. Gastroezofagealna refluksna bolezen. Med Razgl 2004; 43: 261-77.

31. Armstrong D, Talley NJ, Lauritsen K, et al. The role of acid suppression in patients with endoscopy-negative reflux disease: the effect of treatment with esomeprazole or omeprazole. Aliment Pharmacol Ther 2004; 20: 413-21.

32. Dias LM. Pantoprazole - a proton pump inhibitor. Clin Drug Invest 2009; Suppl 2: 3-12.

33. Cheer SM, Prakash A, Faulds D, et al. Pantoprazole: an update of its pharmacological properties and therapeutic use in the management of acid-related disorders. Drugs 2003; 63: 101-33.

34. Wilton LV, Key C, Shakir SA. The pharmacovigilance of pantoprazole: the results of postmarketing surveillance on 11541 patients in England. Drug Saf 2003; 26: 121-32.

35. Brunner G, Athmann C, Schneider A. Long-term, open-label trial: safety and efficacy of continuous maintenance treatment with pantoprazole for up to 15 years in severe acid-peptic disease. Aliment Pharmacol Ther 2012; 36: 37-47.

Received: 21.04.2017

Accepted: 23.05.2017 